\title{
Rhazes (AD 865-925) and his early contributions to the field of pediatrics
}

\author{
Sina Zarrintan ${ }^{1} \cdot$ Annis Shahnaee $^{2} \cdot$ Saeid Aslanabadi ${ }^{3}$
}

Received: 21 April 2017 / Accepted: 12 June 2017 / Published online: 5 July 2017

(C) Springer-Verlag GmbH Germany 2017

"The doctors' aim is to do well, even to our enemies, so much more to our friends, and my profession forbids us to do harm to our kindred, as it is instituted for the benefit and welfare of the human race, and God imposed on physicians the oath not to compose mortiferous remedies.", Rhazes, AD 865-925

\section{Introduction}

Abu Bakr Muhammad ibn Zakariya al-Razi known as Rhazes in the west was an Iranian scholar, researcher, physician, and alchemist. He was born in Rey, a city nearby Tehran. He lived from 865 to 925 [1-3]. Rhazes was among the outstanding physicians and medical scholars in his time and made notable contributions in the fields of theoretical and practical medicine $[4,5]$. Because of his expertise and reputation, he was appointed as the chief of the main hospital in Baghdad and for a while as a court physician $[6,7]$.

Rhazes was among the two greatest physicians in medieval Iran. Rhazes was followed by Avicenna (937-1037) and was regarded by him as an honorable and distinguished scholar [8]. Rhazes followed Hippocrates and Galen in his works, but Rhazes combined textual medicine with his clinical observations [9]. Despite this, Rhazes rejected several claims made

Sina Zarrintan

s.zarrintan@yahoo.com

1 Department of General Surgery, Faculty of Medicine, Tabriz University of Medical Sciences, Tabriz 51664, Iran

2 School of Pharmacy, Tabriz University of Medical Sciences, Tabriz, Iran

3 Division of Pediatric Surgery, Children's Hospital, Tabriz University of Medical Sciences, Tabriz, Iran by Greek physicians regarding the Greek language and medicine. Although he was a follower of the Galenic thought, Rhazes rejected many teachings of Galen in his Shukuk book "Doubts about Galen (Shukuk'ala alinusor)" [1, 10, 11]. That is why he is considered as a physician who practiced evidence-based medicine (EBM) in his medical career early in the history of medicine [10].

It is believed that Rhazes was the most original and the greatest of all the physicians of his time [12-14]. As a teacher of medicine, Rhazes attracted students of all backgrounds and interests and was said to be compassionate and devoted to the service of his patients, whether rich or poor [15]. Through translation, his medical works became known among medieval European practitioners and profoundly influenced medical education in the West. Some sections of his publications became parts of the medical curriculum in Western universities $[16,17]$.

The aim of this article is to review the early contributions of Abu Bakr Muhammad Zakariya al-Razi to the pediatrics and diseases of children. We would like to emphasize on the great achievements of Rhazes in the diseases of children in the medieval period and show his role as a physician of children and a pediatric scholar at that time.

\section{Books and articles of Rhazes on medicine}

The most prominent of his books was the nine-volume encyclopedia "The Virtuous Life (al-Hawi)" which is known in Europe also as "The Large Comprehensive" or "Continens Liber (Jameh-al-Kabir)" [18, 19]. This book contains considerations in various medical subjects and also criticisms on Greek and Aristotelian concepts [1]. This work expresses many innovative views, and thus, many scholars consider Rhazes the greatest physician of the Middle Ages [19, 20]. 
Even more influential in Europe was Rhazes' book "Liber ad Almansoris," a short general textbook on medicine in ten chapters which he had dedicated to the Samanid prince Abu Salih al-Mansur ibn Ishaq, governor of Rayy. It became one of the most widely read medieval medical manuals in the West. In the Renaissance, many editions of it were printed with commentaries by the prominent physicians of the day, such as Andreas Vesalius (AD 1514-1564) [1, 21].

The other valuable book by Rhazes was "For one without a doctor (Man la Yahduruhu al-Tabib" which was a medical advisor for the general public. Rhazes was possibly the first Iranian physician to write a home medical manual [18]. Rhazes dedicated this book to the poor, travelers, and normal citizens when a doctor was not available [22]. This book consisted of common symptoms and some of the illnesses such as headache, colds, coughing, and melancholy and diseases of the eye, ear, and stomach. Diets and drug components were described for these situations. This book is of considerable value regarding the history of pharmacy because similar books were published to guide general people and advise prescriptions by the scholars after Rhazes [23]. This book is also known as "Tibb al-Fuqara" which means "Medicine for the Poor."

In his book "Doubts about Galen (Shukuk 'ala Alinusor)," Rhazes rejected several claims of Greek physicians and reported that Galen's descriptions did not agree with his own clinical observations in numerous aspects $[1,10,18]$. Rhazes describes his enthusiasm in writing this book by this saying: "I prayed to God to direct and lead me to the truth in writing this book. It grieves me to oppose and criticize the man Galen from whose sea of knowledge I have drawn much. Indeed, he is the Master and I am the disciple. Although this reverence and appreciation will and should not prevent me from doubting, as I did, what is erroneous in his theories. I imagine and feel deeply in my heart that Galen has chosen me to undertake this task, and if he were alive, he would have congratulated me on what I am doing. I say this because Galen's aim was to seek and find the truth and bring light out of darkness. I wish indeed he were alive to read what I have published." [24].

Rhazes wrote over 200 books and treatises on medicine, alchemy, philosophy, and religion. In addition to "The Virtuous Life," "For one without a doctor," and "Doubts about Galen," the most notable of his books and treatises on medicine were "The Diseases of Children," "Proving the Science of Medicine (Isbat-e-Elm-e-Pezeshki)," "Outcome of the Science of Medicine (Daramad-i Bar Elm-e Pezeshki)," "The book on formation of small stones: Stones in the kidney and bladder (Ketab-dar Padid Amadan-e-Sangrizeh)," "The book on Pain in Intestine (Ketab-dar Dard-e-Roudeha)," "About the Liver (Dar Hey'ateh Kabed)," "About the Heart (Dar Hey'ateh Ghalb), and "A Treatise on Smallpox and Measles (al-Judari wa al-Hasbah" [1, 10, 18, 23, 24]. Rhazes also gave an early example of a clinical trial, when he divided his patients suffering from meningitis (al-sirŝam) into two groups. He treated one group with bloodletting while the other group did not get the treatment $[4,17,25,26]$.

\section{Early contributions of Rhazes to pediatrics}

As a physician and scholar, Rhazes wrote a book on smallpox and measles providing clinical characteristics of the diseases [18]. This book was named "al-Judari wa al-Hasbah" which is translated into English as "A Treatise on Smallpox and Measles." It was the first book which described smallpox and measles as distinct disease in late ninth and early tenth century [27]. Previously smallpox and measles considered together simply as a disease that caused skin rashes, but through precise observations, Rhazes found and recorded the differences in their cutaneous manifestations and any associated systemic symptoms. Thus, he proposed for the first time that they were indeed two distinct diseases $[28,29]$. " $A$ Treatise on Smallpox and Measles" was translated into Latin, Byzantine Greek, and various modern languages [27, 29]. It has been reprinted in English in recent decades by a number of publishers [29].

Rhazes composed his treatise on smallpox and measles in 14 chapters. As he explains in the introduction of this book, he wrote this book upon visiting a nobleman at that time and having a brief discussion with him on the topic. Rhazes admires that man's intelligence and prays for him in the first part of the book. He hopes to provide modern and accurate information in his book regarding all information about measles and smallpox [30].

Rhazes included Galen's works on smallpox and measles in his book but he also added his own clinical experiences to differentiate these two diseases in children. In his book, Rhazes explain "As to any physician who says that the excellent Galen has made no mention of smallpox, and was entirely ignorant of this disease, surely he must be one of those who have either never read his works at all, or who have passed over them very curiously" [29, 30].

In chapter III of his book on smallpox and measles, "On the Symptoms Which Indicate the Approaching Eruption of the Smallpox and Measles," Rhazes state the differences of clinical manifestations of the two diseases. He states that "The eruption of smallpox is preceded by a continued fever, pain in the back, itching in the nose and nightmares during sleep. These are the more acute symptoms of its approach together with a noticeable pain in the back accompanied by fever and an itching felt by the patient all over his body. A swelling of the face appears, which comes and goes, and one notices an overall inflammatory color noticeable as a strong redness on both cheeks and around both eyes. One experiences a heaviness of the whole body and great restlessness, which expresses 
itself as a lot of stretching and yawning. There is a pain in the throat and chest and one finds it difficult to breathe and cough. Additional symptoms are: dryness of breath, thick spittle, and hoarseness of the voice, pain and heaviness of the head, restlessness, nausea and anxiety. Altogether one experiences heat over the whole body, one has an inflamed color and one shows an overall shining redness, with a very pronounced redness of the gums." [30].

In addition to his treatise on smallpox and measles, Rhazes published another book "Risāla fi amrāz al-atfāl wa 'I"ianaya bihim" on pediatrics. This book is known in the West as "A Treatise on Pediatric Disease" or "The Diseases of Children" [7, 31, 32]. It is known in Latin as "Practica Puerorum" [18]. This treatise is known as the first book on pediatrics [33]. The book contains 24 chapters and has been translated into Latin, German, Italian, and English. Rhazes has explained a number of infantile and childhood diseases and their remedies in these chapters [31]. Despite the vast progresses that have been made in the field of pediatrics, Rhazes has had great contributions in this field and he is for sure one of the pioneers in pediatrics. This has led some historians to regard him as the father of pediatrics [32]. Figure 1 and cover picture illustrates a Persian painting by Hossein

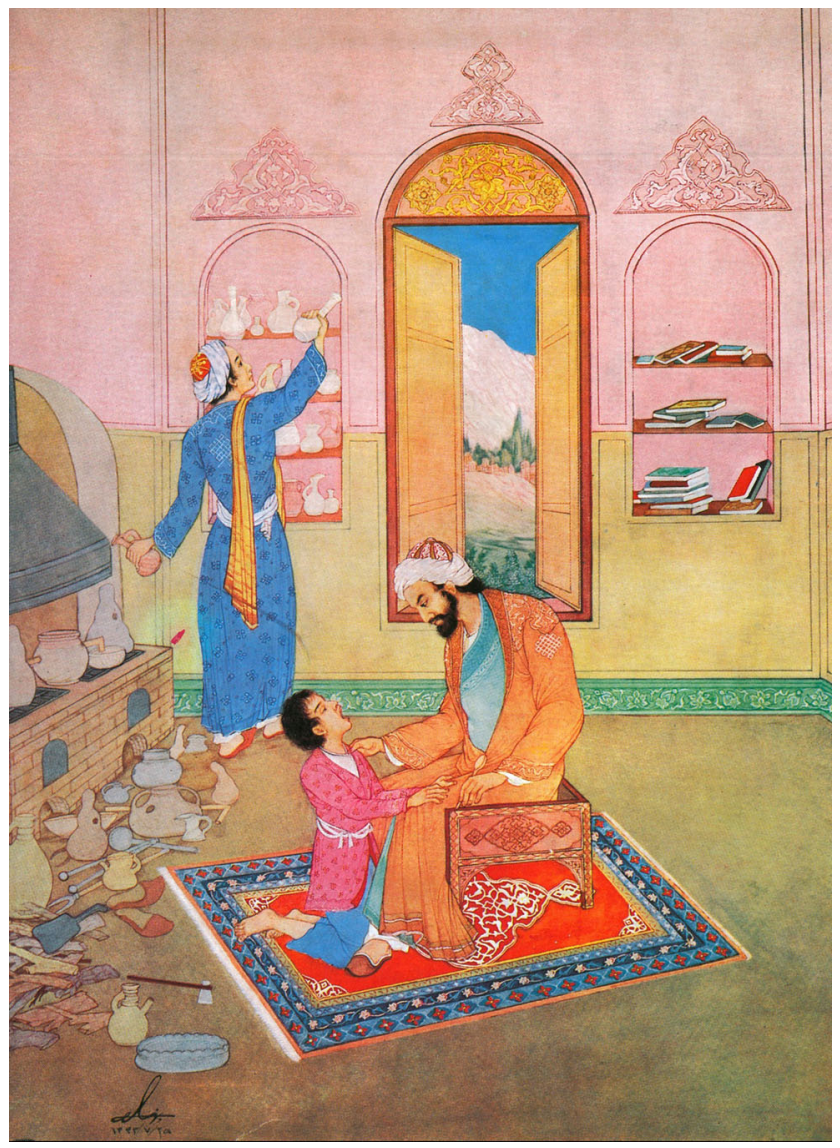

Fig. 1 and cover picture A Persian miniature by Iranian prominent painter Hossein Behzad (1894-1968). In this painting, Rhazes (AD 865925 ) examines a kneeling boy whose mouth was open
Behzad (1894-1968), a prominent Iranian miniature painter. In this painting, Rhazes is examining a kneeling boy who has his mouth open.

\section{Contributions to pediatric neurological diseases and pediatric neurosurgery}

The pediatric clinical entity called "Mater Puerorum" appears first in the Latin translation of Rhazes' "Practica Puerorum" and in his "Liber Continens." He is describing diagnoses of night terrors, or hyperpyretic convulsions, or a slight form of epilepsy [18, 34].

Rhazes was also a pioneer in the field of pediatric neurosurgery. Although he was predominantly a pediatrician, he dealt with the subject of hydrocephalus. A considerable part of his book "Liber Continens" deals with head-related disorders including the hydrocephalus. Although he did not introduce novel concepts of hydrocephalus, he endeavored to improve treatment and knowledge of this condition [35]. He also underlined removing bone fragments in depressed and separated fractures of the cranium along with the protection of the dura [36].

\section{Conclusions}

Rhazes (AD 865-925) was a great Persian physician, scholar, and philosopher of the medieval ages. He has had great contributions to the field of medicine and has been regarded as the best physician of his time. He had considerable contributions to the field of pediatrics and authored the first treatise on this field. We are grateful to this scientist physician for his valuable achievements during the Islamic Golden Ages.

Rhazes' birthday is celebrated in Iran annually on 27th of August as the National Iranian Pharmacists' Day because of his great contributions to the field of chemistry and pharmacy. In addition, Razi (Rhazes) Biomedical Research Festival is held in Iran annually in January since 1995. This festival is the highest academic medical research festival in Iran and distinguished biomedical researchers are awarded by the Iranian president.

\section{Compliance with ethical standards}

Conflicts of interest The authors do not have any conflicts of interest.

\section{References}

1. Tubbs RS, Shoja MM, Loukas M, Oakes WJ (2007) Abubakr Muhammad Ibn Zakaria Razi, Rhazes (865-925 AD). Childs Nerv Syst 23:1225-1226 
2. Shoja MM, Tubbs RS (2007) The history of anatomy in Persia. J Anat 210:359-378

3. Shoja MM, Tubbs RS, Loukas M, Shokouhi G, Ardalan MR (2009) Facial palsy and its management in the Kitab al-Hawi of Rhazes. Neurosurgery 64:1188-1190 discussion 1190-1

4. Zarrintan S, Najjarian F, Tahmasebzadeh S, Aslanabadi S, Zarrintan MH (2014) Abu Bakr Muhammad ibn Zakariya Razi (AD 865925) and early description of clinical trials. Int J Cardiol 174:758 759

5. Golzari SE, Khan ZH, Ghabili K, Hosseinzadeh H, Soleimanpour H, Azarfarin R, Mahmoodpoor A, Aslanabadi S, Ansarin K (2013) Contributions of Medieval Islamic physicians to the history of tracheostomy. Anesth Analg 116:1123-1132

6. Rikhtegar R, Zarrintan S (2014) Neurological letter from Iran. Pract Neurol 14:50-53

7. Modanlou HD (2008) A tribute to Zakariya Razi (865-925 AD), an Iranian pioneer scholar. Arch Iran Med 11:673-677

8. Shamsi M, Haghverdi F, Changizi Ashtiyani S (2014) A brief review of Rhazes, Avicenna, and Jorjani's views on diagnosis of diseases through urine examination. Iran J Kidney Dis 8:278-285

9. Compier AH (2012) Rhazes in the renaissance of Andreas Vesalius. Med Hist 56:3-25

10. Zarrintan S, Aslanabadi S, Rikhtegar R (2013) Early contributions of Abu Bakr Muhammad Ibn Zakariya Razi (865-925) to evidencebased medicine. Int J Cardiol 168:604-605

11. Alvarez Millan C (1999) Greco-Roman case histories and their influence on Medieval Islamic clinical accounts. Soc Hist Med 12:19-43

12. Daghestani AN (1997) Images in psychiatry. al-Razi (Rhazes), 865-925. Am J Psychiatry 154:1602

13. Nezhad GS, Dalfardi B (2014) Rhazes (865-925 AD), the icon of Persian cardiology. Int J Cardiol 177:744-747

14. Andelman Y (1993) Rhazes. Ann Rheum Dis 52:698

15. El Gammal SY (1995) Rhazes contribution to the development and progress of medical sciences. Bull Indian Inst Hist Med Hyderabad 25:135-149

16. Arzumetov IS, Margulis GM (1965) Rhases (Abu Bakr Muhammad ibn Zakariya al-Razi) — outstanding physician of the oriental world (1,100 anniversary of birth). Sov Zdravookhr 24:6668

17. Iskandar A (2008) Al-Razi. In: Selin H (ed) Encyclopaedia of the history of Science, technology, and medicine in non-western cultures. Springer, Dordrecht, pp 155-156

18. Amr SS, Tbakhi A (2007) Abu Bakr Muhammad Ibn Zakariya al Razi (Rhazes): philosopher, physician and alchemist. Ann Saudi Med 27:305-307

19. Azeez Pasha M (1976) Al-Hawi (Liber Continens) of Ar-Razi, Abu Bakr Muhammed Bin Zakariya; synopsis of the fourteenth volume (part I). Bull Indian Inst Hist Med Hyderabad 6:233-239
20. Azeez Pasha M (1977) Al-Hawi (Liber Continens) of Ar-Razi, Abu Bakr Muhammed Bin Zakariya; synopsis of the fourteenth volume. Part II. Bull Indian Inst Hist Med Hyderabad 7:131-137

21. Al-Razi, the Clinician. Islamic Culture and the Medical Arts (2011) US National Library of Medicine. Accessed online on May 31, 2017; http://www.nlm.nih.gov/exhibition/islamic_medical/ islamic $06 . \mathrm{html}$

22. Tayarani-Najaran Z, Tayarani-Najaran N, Emami SA (2014) The history of Islamic medicine at a glance. In: Watson RR, Preedy VR, Zibadi S (eds) Polyphenols in human health and disease. Elsevier, San Diego, pp 17-28

23. Meri JW (2006) Medieval Islamic civilization: an encyclopedia. Volume 1. Routledge, New York, NY, USA, pp 671-3

24. Hajar R (2013) The air of history (part IV): great Muslim physicians al Rhazes. Heart Views 14:93-95

25. Iskandar AZ (1985) Development of medical education among the Arabic-speaking peoples. In: north JD, Roche JJ (eds). The light of nature: essays in the history and philosophy of Science presented to A.C. Crombie. Martinus Nijhoff publishers: Dordrecht, The Netherlands, pp 16-7

26. Young MJL (1990) Religion, learning and Science during Abbasid period. Press Syndicate of the University of Cambridge, New York, pp 375-377

27. The Editors of Encyclopedia Britannica. Al-Razi: Persian Physician. Encyclopedia Britannica. Accessed online on May 31, 2017; http://www.britannica.com/EBchecked/topic/492607/alRazi

28. Temkin O (1942) A medieval translation [in Latin] of Rhazes' clinical observations. Bulletin of the History of Medicine, pp:102-117

29. Rhazes. A Treatise On The Small-pox And Measles. Nabu Press, USA (Reprinted in 2011).

30. Abū Bakr Muhammad ibn Zakarīyā Rāzī. A Treatise on the smallpox and measles. Translated from Original Arabic into English by Greenhell WA (1847) Printed for the Sydenham society. London, UK, pp 23-24

31. Arabzadeh A, Tafti MA, Zarshenas MM (2014) The very early textbook of pediatrics: Tadbir-Al-Sebyān. J Integr Med 12:531-532

32. Ashcans DW (2003) Arab roots of European medicine. Heart Views 4:9

33. Radbill SX (1971) The first treatise on pediatrics. Am J Dis Child 122:369-376

34. Kottek SS (1981) Mater puerorum'. A medieval naming for an enigmatic children's disease. Eur J Pediatr 137:75-79

35. Aciduman A, Belen D (2009) Hydrocephalus and its treatment according to Rhazes historical vignette. J Neurosurg Pediatr 3: $161-165$

36. Acıduman A, Așkit C, Belen D (2014) Medieval times' influencing figure Rhaze's approach to head injuries in Liber Almansoris. World Neurosurg 82:1325-1330 